\title{
Metformin modifies glutamine metabolism in an in vitro and in vivo model of hepatic encephalopathy
}

\author{
Antonio Gil-Gómez', Ana Isabel Gómez-Sotelo², Isidora Ranchal², Ángela Rojas', Marta García-Valdecasas', \\ Rocío Muñoz-Hernández' ${ }^{1}$ Rocío Gallego-Durán' , Javier Ampuero ${ }^{1,3}$ and Manuel Romero-Gómez ${ }^{1,3}$ \\ ${ }^{1}$ Instituto de Biomedicina de Sevilla (IBiS). Hospital Universitario Virgen del Rocío/CSIC/Universidad de Sevilla. Sevilla, Spain. CiberEHD. ${ }^{2}$ Unit for \\ Clinical Management of Digestive Diseases. Hospital Universitario de Valme. Sevilla, Spain. ${ }^{3}$ Unit for the Clinical Management of Digestive Diseases \\ Hospital Universitario Virgen del Rocío. Sevilla, Spain
}

Received: 18/04/2017 - Accepted: 01/02/2018

Correspondence: Manuel Romero-Gómez. Unit for the Clinical Management of Digestive Diseases. Hospital Universitario Virgen del Rocío. Av. Manuel Siurot, s/n. 41013 Sevilla, Spain. e-mail: mromerogomez@us.es

\section{ABSTRACT}

Aim: to analyze the effect of metformin on ammonia production derived from glutamine metabolism in vitro and in vivo.

Methods: twenty male Wistar rats were studied for 28 days after a porto-caval anastomosis $(n=16)$ or a sham operation $(n=4)$. Porto-caval shunted animals were randomized into two groups $(\mathrm{n}=8)$ and either received $30 \mathrm{mg} / \mathrm{kg} / \mathrm{day}$ of metformin for two weeks or were control animals. Plasma ammonia concentration, Gls gene expression and K-type glutaminase activity were measured in the small intestine, muscle and kidney. Furthermore, $\mathrm{Caco} 2$ were grown in different culture media containing glucose/glutamine as the main carbon source and exposed to different concentrations of the drug. The expression of genes implicated in glutamine metabolism were analyzed.

Results: metformin was associated with a significant inhibition of glutaminase activity levels in the small intestine of porto-caval shunted rats $(0.277 \pm 0.07 \mathrm{IU} / \mathrm{mg}$ vs $0.142 \pm$ $0.04 \mathrm{IU} / \mathrm{mg}$ ) and a significant decrease in plasma ammonia $(204.3 \pm 24.4 \mu \mathrm{g} / \mathrm{dl}$ vs $129.6 \pm 16.1 \mu \mathrm{g} / \mathrm{dl})$. Glucose withdrawal induced the expression of the glutamine transporter SLC1A5 (2.54 \pm 0.33 fold change; $p<0.05)$. Metformin use reduced MYC levels in Caco2 and consequently, SLC1A5 and GLS expression, with a greater effect in cells dependent on glutaminolytic metabolism.

Conclusion: metformin regulates ammonia homeostasis by modulating glutamine metabolism in the enterocyte, exerting an indirect control of both the uptake and degradation of glutamine. This entails a reduction in the production of metabolites and energy through this pathway and indirectly causes a decrease in ammonia production that could be related to a decreased risk of HE development.

Key words: Hepatic encephalopathy. Metformin. Ammonia. Glutaminase. Glutamine. Cirrhosis. ASCT2. mTOR. Porto-caval anastomosis.

\section{INTRODUCTION}

Hepatic encephalopathy (HE) is a common entity caused by liver failure that results from acute and chronic disorders such as hepatitis and cirrhosis and is one of the main complications of cirrhosis (1). This syndrome involves neuropsychiatric dysfunction ranging from subtle psychological abnormalities to profound coma due to a metabolic disturbance (2). Clinical studies strongly suggest a major role of ammonia in the development of brain disturbances in liver disease and systemic hyperammonemia is commonly found in patients with cirrhosis and HE (3). The pathophysiological mechanisms include alteration of blood-brain-barrier permeability, cytokine production, changes in neurotransmitter synthesis and release, neuronal oxidative stress, impaired mitochondrial function and osmotic disturbances resulting from astrocytic metabolism (4).

Ammonia is mainly produced in the small intestine during protein digestion and nitrogen metabolism carried out by epithelial cells and bacterial flora (5). The majority of the gut ammonia is a by-product derived from glutamine metabolism into glutamate and ammonia by the enzyme glutaminase (EC 3.5.1.2) (4). In a damaged liver, especially a cirrhotic one which can have up to four times more ammonia producing activity, hepatocytes cannot handle the overload and urea cycle is saturated (6). Neural amino acid transporter $\mathrm{B}(0)$ (ATB[0] or ASCT2 encoded by SLC1A5) is a glutamine transporter that also plays an important role in metabolism and amino acid homeostasis of cells in most tissues and it may be relevant in glutamine-derived ammonia production (7). Both proteins (ASCT2 and glutaminase) are critical for glutaminolytic

Gil-Gómez A, Gómez-Sotelo Al, Ranchal I, Rojas Á, García-Valdecasas M, Muñoz-Hernández R, Gallego-Durán R, Ampuero J, Romero-Gómez M. Metformin modifies glutamine metabolism in an in vitro and in vivo model of hepatic encephalopathy. Rev Esp Enferm Dig 2018;110(7):427-433

DOI: $10.17235 /$ reed.2018.5004/2017 
metabolism, which in turn is regulated by the MYC proto-oncogene, a master regulator of metabolism (8). One of the most important signaling functions of ASCT2 is the link with the mammalian target of the rapamycin (mTOR) pathway. This integrates signals from five major routes, including growth factors, cellular stress, energy status, oxygen and amino acids (9). In fact, it is thought that glutamine metabolism could sustain cell energy requirements and be essential for growth and viability when regulated rapid cell division is required. This is important in processes such as wound healing (i.e., liver regeneration), immune responses to specific antigens or even cancer (10). Furthermore, stress and hyperammonemia could rapidly increase the ratio a-ketoglutarate/citrate, triggering enhanced glutaminolysis and sensitizing the cells to the action of several agents (11).

Almost $95 \%$ of cirrhotic patients may be glucose intolerant and type 2 diabetes mellitus was found in a third of cases (12). Furthermore, the association of diabetes and insulin resistance in $\mathrm{HE}$ risk and cirrhosis progression has been previously demonstrated. These diseases have been related to enhanced cytokine production and an inflammatory state, an increased ammonia production via a glutaminase activity increase and constipation (13-15). Metformin is a widely used antihyperglycemic drug that has demonstrated pleiotropic effects and has also been reported to reduce the chronic inflammatory response by inhibiting TNF $\alpha$ production (16-17). It also blocks endogenous reactive oxygen species production by interfering with mitochondrial complex I activity (18). Ampuero et al. (2012) demonstrated in a retrospective study that metformin-exposed cirrhotic patients had an eight-fold lower HE risk (19). Furthermore, they also demonstrated an in vitro glutaminase activity reduction followed by an ammonia production decrease after metformin treatment.

The aim of this study was to analyze the effect of metformin on glutaminase (GLS) gene expression and K-type glutaminase (KGA) enzyme activity in a rat model of $\mathrm{HE}$ and to determine the impact of the drug on glutamine metabolism.

\section{MATERIAL AND METHODS}

\section{Experimental design}

\section{In vivo study}

All animals used in the study were maintained before, during and after experiment according to the directive 2010/63/EU regarding the use of animals for experimentation and other scientific purposes (Royal Decree-Law $53 / 2013$, of February 8, laying down basic rules for the protection of animals used for experimental and other scientific purposes, including teaching). All animal procedures were performed with the approval of the University of Seville Animal Ethics Committee. All experiments were conducted on the premises of Service Production and Animal Experimentation of the Institute of Biomedicine of Seville/HUVR (registered and authorized center no. ES410910008015). All guidelines and regulations concerning the housing conditions of animal experimentation were fulfilled. Appropriate measures were taken to minimize the pain or discomfort of animals.
Twenty maleWistar rats with a body weight of $400 \pm 24 \mathrm{~g}$ were individually housed in standard conditions (12 h/12 h light/ dark cycle at $23 \pm 2{ }^{\circ} \mathrm{C}, 50 \%$ humidity) with ad libitum access to food and water. These animals underwent a sham operation (n $=4$ ) or porto-caval shunt (PCS) ( $n=16)$ following the method proposed by Numata (20). Two weeks after surgery, operated rats were randomized into two groups; PCS as a control group $(n=8)$ and PCS + Met $(n=8)$. The latter group received $30 \mathrm{mg} / \mathrm{kg} /$ day of metformin (Acofarma, Madrid, Spain) with the food during the experimental period of 14 days. Animals were sacrificed by exsanguination and blood was withdrawn from the descending aorta and immediately put into ice cold EDTA tubes, centrifuged at 3,000 rpm at $4^{\circ} \mathrm{C}$, and plasma was collected. Muscle, kidneys and small intestine (scrapings of intestinal villi) were collected and washed in cold phosphate saline buffer. Approximately $100 \mathrm{mg}$ of tissue were processed for enzymatic activity as described below. The remaining tissue was stored at $-80^{\circ} \mathrm{C}$ until RNA extraction.

\section{In vitro study}

The human colonic epithelial cell line $\mathrm{Caco} 2$ was maintained in DMEM Low Glucose (w/glucose, w/o glutamine and w/ sodium pyruvate) or DMEM (w/o glucose, w/glutamine and w/o sodium pyruvate), supplemented with $100 \mathrm{ml} / \mathrm{l}$ fetal bovine serum, $100 \mathrm{U} / \mathrm{ml}$ penicillin, $100 \mu \mathrm{g} / \mathrm{ml}$ streptomycin, non-essential amino acids and $2 \mathrm{mmol} / \mathrm{l} \mathrm{L-Glutamine}$ (ThermoFisher, MA, USA) in $50 \mathrm{ml} / \mathrm{l} \mathrm{CO}$ at $37^{\circ} \mathrm{C}$. Cell concentration was determined with a Neubauer chamber. Cell assays were initiated 24 hours after seeding. Caco2 $(10,000$ cells $\left./ \mathrm{cm}^{2}\right)$ were cultured in the presence of 2,5 and $10 \mathrm{mM}$ of metformin, based on the work of Javeshghani et al. (21). An aliquot of supernatant was collected for every group 24 hours after initiation of the experiment. After 48 hours, cells were collected and stored at $-80^{\circ} \mathrm{C}$ until assayed.

\section{Gene expression}

Total RNA was extracted from cell culture or tissue homogenization using TRIzol (22). Reverse transcription reactions were performed using the QuantiTect ReverseTranscription Kit (Qiagen, Hilden, Germany) according to the manufacturer's protocol. Gene expression was analyzed by quantitative polymerase chain reaction (qPCR) using the SensiFAST ${ }^{\text {TM }}$ SYBR ${ }^{\circledR}$ Lo-ROX Kit (Bioline, MA, USA) and the Illumina Eco Real-Time PCR System (Illumina, CA, USA). Nucleic acid concentration was measured in a Qubit 2.0 Fluorometer using kits for the specific measurement of RNA and DNA (Qubit ${ }^{\circledR}$ dsDNA HS Assay Kit, Qubit ${ }^{\circledR}$ RNA HS Assay Kit) (ThermoFisher, MA, USA). Glyceraldehyde 3-phosphate dehydrogenase (Gapdh) was used as a housekeeping gene in rat and ribosomal RNA 18S (RNA18S5) in Caco2. Gene expression levels of GLS, MYC proto-oncogene (MYC), mTOR, SLC1A5 and GIs were determined by the Delta Ct method, assuming a high efficiency of the reaction. Fold change was calculated as the sample/control ratio in three independent experiments and values were expressed as the mean \pm SEM.

\section{Biochemical measurements}

Ammonia was measured in cell culture supernatant and in rat plasma immediately after collection following the gluta- 
mate-dehydrogenase enzymatic assay in a COBAS Integra ${ }^{\circledR}$ 700 (ROCHE, Switzerland).

\section{Enzyme activity}

Tissue samples from the small intestine (ileum and duodenum), muscle and kidney were homogenized within two hours after sacrifice using homogenization buffer (sucrose $320 \mathrm{mM}$, Trizma-HCl $10 \mathrm{mM}$, PMSF $0.2 \mu \mathrm{M}$, EDTA $1 \mathrm{mM}$, $\mathrm{pH}$ 7.4) (Sigma-Aldrich ${ }^{\circledR}, \mathrm{MO}$, USA) before centrifugation at $12,000 \mathrm{rpm}$ for $10 \mathrm{~min}$ at $4{ }^{\circ} \mathrm{C}$. The mitochondrial-enriched pellet was then suspended in incubation buffer (sucrose 70 mM, EGTA 1 mM, mannitol 210 mM, K ${ }_{2} \mathrm{HPO}_{4} 150 \mathrm{mM}, \mathrm{pH}$ 8) (Sigma-Aldrich ${ }^{\circledR}, \mathrm{MO}$, USA) and exposed to an ultrasonic cell disruptor to ensure the rupture of all cell and mitochondrial membranes and the release of free glutaminase from the mitochondria. Protein concentration was measured using the Bradford method (23).

Glutaminase activity assays were performed following the colorimetric protocol described by Heini et al. (24). Specific activity of the enzyme was expressed in international units (IU) per milligram of total homogenate of protein. One IU was defined as a micromole of substrate transformed per minute.

\section{Statistical analysis}

Continuous variables are described as the mean and the error of a minimum of three independent experiments. Data were compared using the ANOVA test with the Tukey's test as post-hoc multiple comparison analyses. The Student's t-test for unpaired samples was used for comparisons between two groups. $p$ values $p<0.05\left({ }^{*}\right)$ and $p<0.01\left(^{* *}\right)$ were considered as statistically significant. The SPSS (version 21.0; SPSS, Inc., IL, USA) statis- tical package was used in all analyses and graphs were generated using GraphPad PRISM (version 6.0, GraphPad Software, Inc, CA, USA).

\section{RESULTS}

\section{Metformin and ammonia production}

In PCS rats, metformin treatment for two weeks significantly reduced ammonia levels in plasma. Sham-operated rats had a mean of $110.8 \pm 16.1 \mu \mathrm{g} / \mathrm{dl}$ of plasma ammonia. These levels were increased in the PCS-animal model $(p=$ $0.025)$ and significantly decreased after metformin treatment $(204.3 \pm 24.4 \mu \mathrm{g} / \mathrm{dl}$ vs $129.6 \pm 16.1 \mu \mathrm{g} / \mathrm{dl} ; \mathrm{p}=0.038)$, reaching levels similar to sham animals (Fig. 1A).

In the in vitro model after 24 hours of incubation, a dose-dependent decrease in the production of ammonia was found in the groups treated with 2,5 and $10 \mathrm{mM}$ of metformin in comparison to the control (Fig. 1B).

\section{Glutaminase expression and activity}

As shown in figure 2, no changes in Gls gene expression levels were associated with PCS or metformin use in rats (Fig. 2A). However, PCS induced an increase in KGA activity in peripheral tissues such as kidney $(0.153$ $\pm 0.05 \mathrm{lU} / \mathrm{mg}$ vs $0.337 \pm 0.08 \mathrm{lU} / \mathrm{mg})$ and muscle $(0.015 \pm$ $0.005 \mathrm{IU} / \mathrm{mg}$ vs $0.086 \pm 0.026 \mathrm{IU} / \mathrm{mg} ; \mathrm{p}<0.05)$ compared to sham operation (Fig. 2B). In addition, a reduction in KGA activity was observed after metformin treatment in the small intestine $(0.277 \pm 0.07 \mathrm{IU} / \mathrm{mg}$ vs $0.142 \pm 0.04$ $\mathrm{IU} / \mathrm{mg})$ and muscle $(0.086 \pm 0.026 \mathrm{IU} / \mathrm{mg}$ vs $0.054 \pm 0.002$ $\mathrm{IU} / \mathrm{mg})$, but not in kidney $(0.337 \pm 0.08 \mathrm{IU} / \mathrm{mg}$ vs $0.286 \pm$ $0.08 \mathrm{IU} / \mathrm{mg}$ ) (Fig. 2B). However, these data did not reach statistical significance.
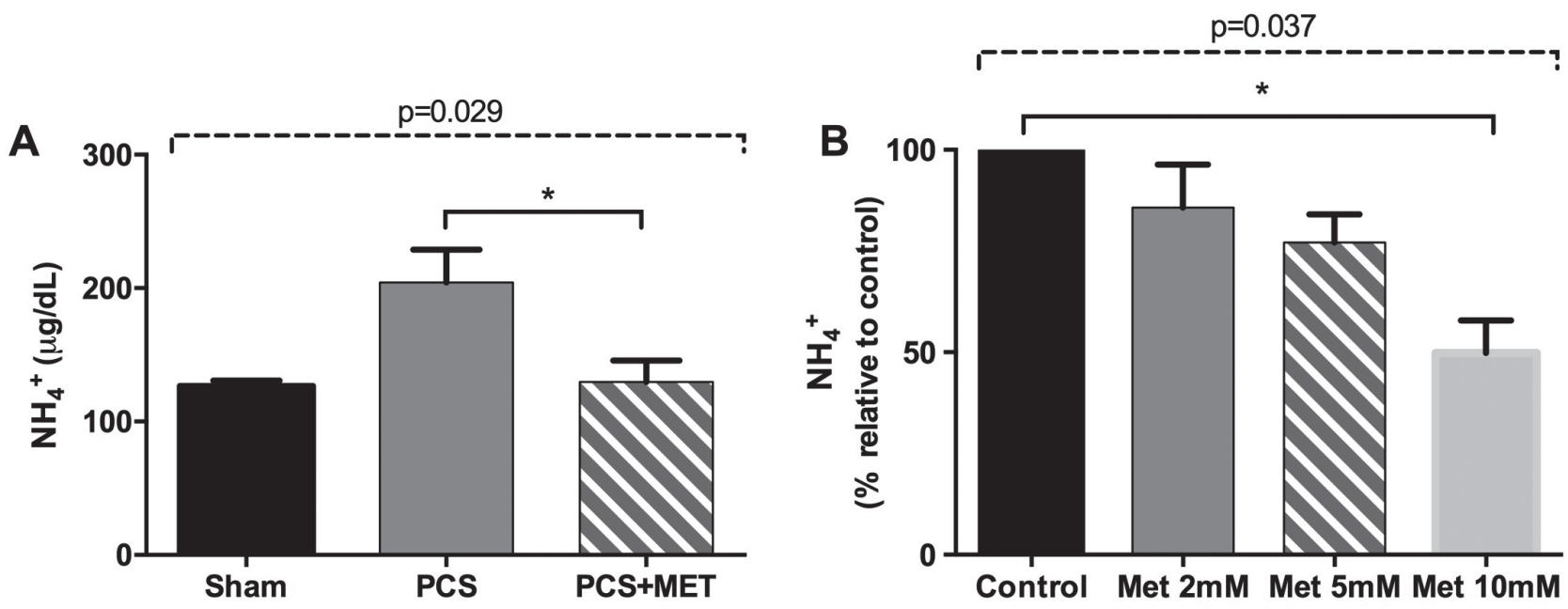

Fig. 1. Ammonia concentrations in plasma of PCS rats and cell culture. A. Plasma ammonia levels in sham rats ( $n=4)$, PCS $(n=8)$ or PCS + metformin (30 mg/kg/day) $(n=8)$ expressed as $\mu \mathrm{g} / \mathrm{dl}$; ${ }^{*} p<0.05$. Outlier trimming (exclusion) at the $5^{\text {th }}$ and $95^{\text {th }}$ percentile was performed for every group in the analysis. $B$. The percentage of ammonia concentration in the culture media of Caco2 exposed to 2, 5 and $10 \mathrm{mM}$ of metformin compared with non-treated cells in three independent replicates. Differences between groups were assessed by ANOVA (dashed line) with Tukey's post-hoc test (continuous line); ${ }^{*} p<0.05$. Data are expressed as means \pm SEM. 

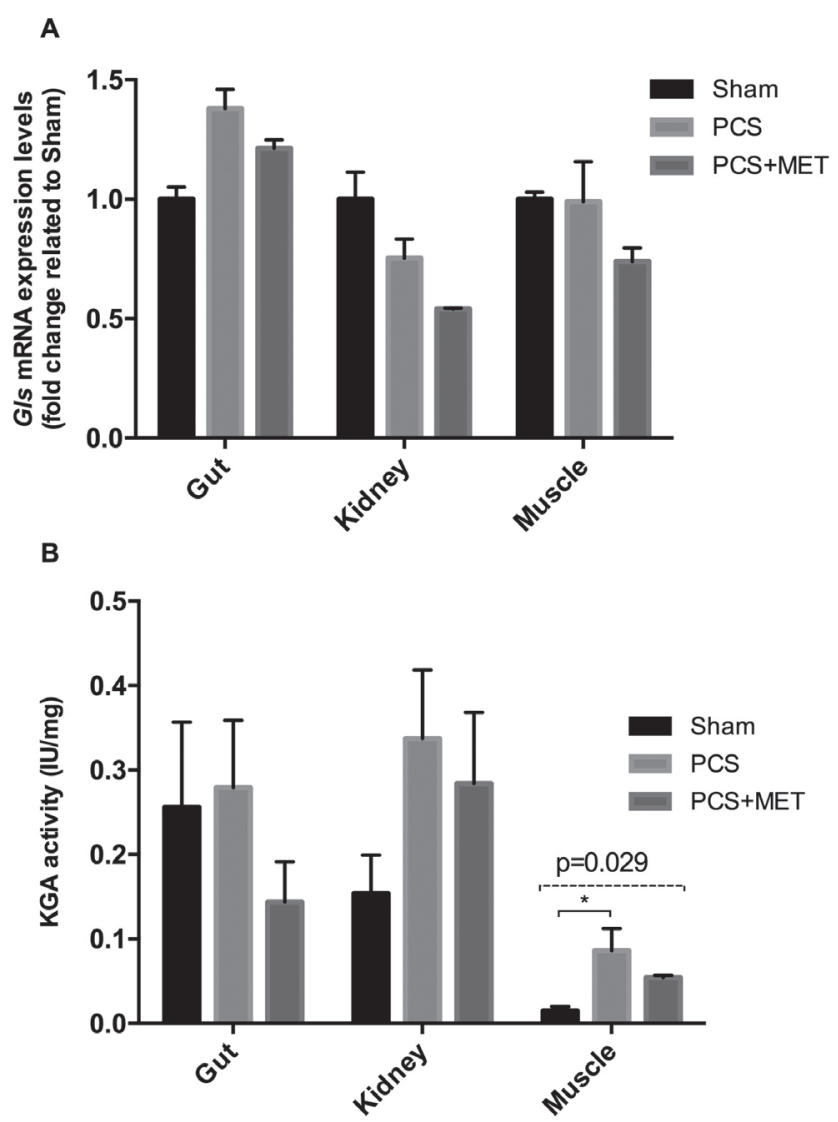

Fig. 2. Changes in gene expression and activity of $K$-type glutaminase in different tissues. A. Gls mRNA expression levels in PCS rats $(n=8)$ and PCS + metformin $(30 \mathrm{mg} /$ $\mathrm{kg} /$ day) $(n=8)$ expressed as fold change compared with the sham group $(n=4)$ in the small intestine, kidney and muscle. B. KGA activity levels expressed as IU/mg. Data are the mean value \pm SEM and the differences between groups were assessed by ANOVA with Tukey's post-hoc test; ${ }^{*} p<0.05$.

\section{Metformin and glutamine metabolism in vitro}

Despite the fact that ammonia was measured at 2, 5 and $10 \mathrm{mM}$, we chose 2 and $5 \mathrm{mM}$ for gene expression level analysis based on the results obtained in the proliferation MTT assay (data not shown). Treatment with $5 \mathrm{mM}$ metformin for 48 hours produced a slight downregulation both in mTOR and SLC1A5 expression in Caco2 with access to glucose and glutamine $(0.49 \pm 0.03$ and $0.59 \pm 0.01$ fold change respectively; $p<0.05)$. However, no significant changes were found for the other genes analyzed, neither at $5 \mathrm{mM}$ nor $2 \mathrm{mM}$ doses (Fig. 3A).

As shown in figure $3 \mathrm{~B}$, the absence of glucose in the medium induced the expression of SLC1A5 in comparison to cells with free access to both glucose and glutamine $(2.54$ \pm 0.33 fold change; $p<0.05$ ) (Fig. 3B). In the context of glucose deprivation, metformin treatment induced changes in the expression levels of mTOR and MYC in a dose-dependent manner $(0.43 \pm 0.24$ and $0.58 \pm 0.20$ fold change, at $2 \mathrm{mM}[\mathrm{p}=\mathrm{ns}]$ and $0.30 \pm 0.05$ and $0.51 \pm 0.03$ at $5 \mathrm{mM}$ [p < 0.01], respectively). In the same way, GLS and SLC1A5 expression were downregulated after treatment $(0.88 \pm 0.13$

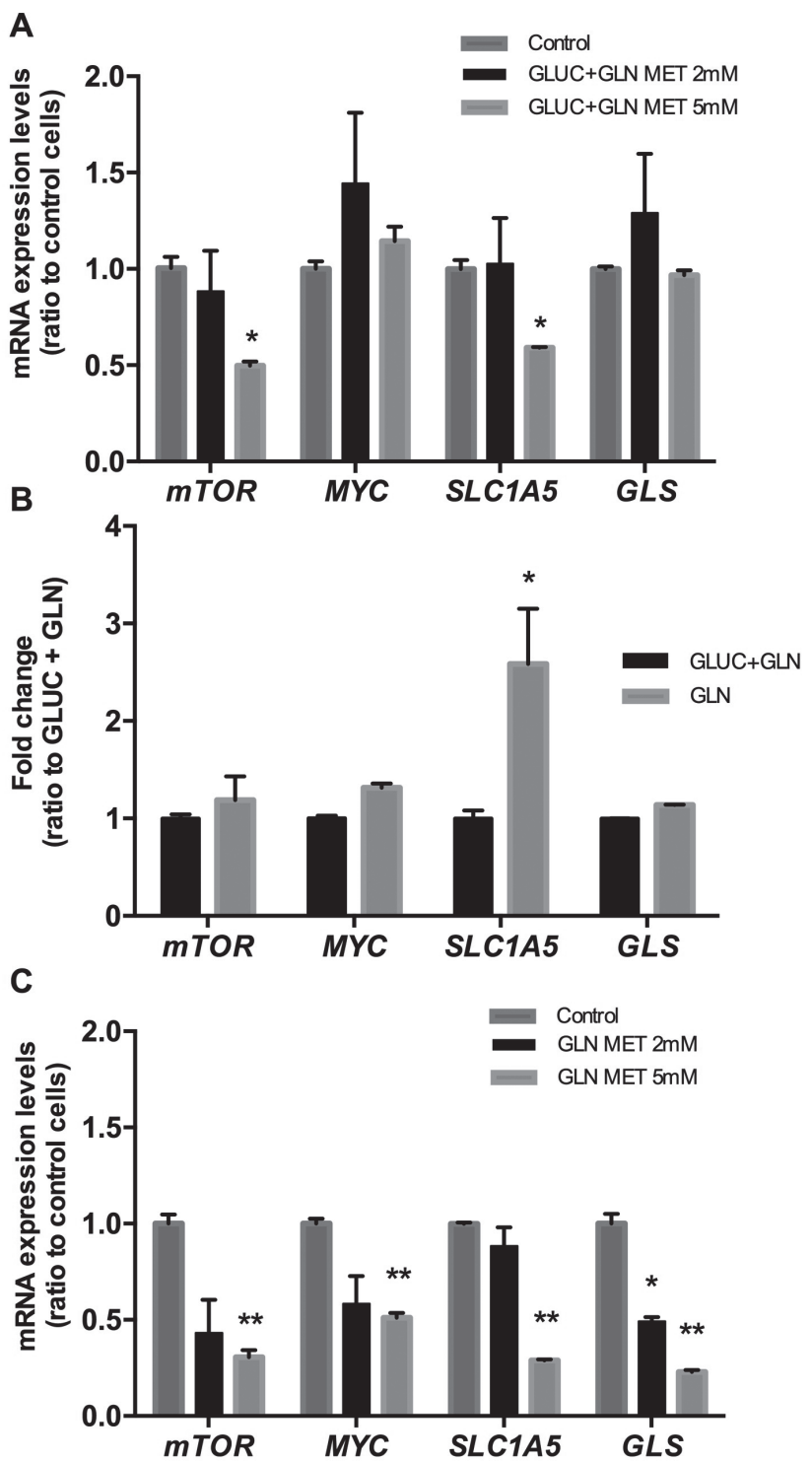

Fig. 3. Changes in gene expression in Caco2. A. Gene expression levels of candidate genes involved in glutamine metabolism in cells exposed to glucosecontaining medium and treated with 2 and $5 \mathrm{mM}$ of metformin. B. Relative mRNA expression levels in Caco2 cells seeded in the presence or absence of glucose (GLN/GLN+GLU). C. Gene expression levels of Caco2 grown in the absence of glucose treated with 2 and 5 $\mathrm{mM}$ of metformin. Data are expressed as means \pm SEM and differences between groups were assessed by the unpaired t-test or ANOVA; ${ }^{*} p<0.05,{ }^{* *} p<0.01$.

[p $=n s]$ and $0.49 \pm 0.03[p<0.05]$ fold change respectively at $2 \mathrm{mM} ; 0.28 \pm 0.01$ and $0.22 \pm 0.01$ at $5 \mathrm{mM}$ [p < 0.01]) (Fig. 3C).

\section{DISCUSSION}

In this proof-of-concept study, we investigated the modulation of ammonia production in the small intestine by analyzing glutaminase expression and activity in an animal model of hepatic encephalopathy. The effect of metformin 
in regulating glutamine metabolism was also assessed. PCS animals show hyperammonemia, alterations of circadian rhythms, different aromatic/branched chain amino acid ratios, decreased brain glucose utilization, oxidative/nitrosative stress and an interrupted function of multiple neurotransmitters similar to HE in human cirrhotic patients (25).

Although circulating levels of ammonia depend on the action of various organs, this study was focused on KGA. The activity of this enzyme in the duodenum has been proposed as the main source of the neurotoxin related to the presence of $\mathrm{HE}$ and the degree of hepatic dysfunction in patients with cirrhosis $(6,26)$. Besides, higher concentrations of metformin were found in the small intestine compared to other tissues or in plasma (up to about $500 \mathrm{mg} / \mathrm{g}$ of tissue). This raises the possibility that the small intestine might be a significant site of action of the drug (27). We previously showed that the increase in ammonia was related to an increased activity of the glutaminase enzyme in the gut of PCS rats. This is consistent with the concept that gut ammonia production is increased in cirrhotic patients after oral glutamine challenge $(6,19)$. In this study, our results indicate that metformin treatment resulted in a reduction of ammonia production reflected by a decrease in glutaminase activity, which was directly measured in plasma and cell culture supernatant. However, this study has some limitations, largely related to its proof-of-concept design. The absence of statistical significance in some points might be due to the low sample size in the in vivo study. Besides, the in vitro study may be performed in more than one cell line. Nevertheless, our data seem to corroborate the influence of this drug on ammonia homeostasis, postulating it as an alternative therapy against $\mathrm{HE}$. The fact that no changes were found in glutaminase gene expression suggests a posttranscriptional effect, as proposed previously (28). In accordance with our data, Jover-Cobos et al. showed a reduction in glutaminase activity in the gut after treatment with ornithine phenylacetate in bile-duct ligated rats (29). However, since this study was conceived as a proof of concept, further studies with a larger sample size are needed.

Several compounds have recently been tested that inhibit KGA such as DON (6-diazo-5-oxy-i-norleucine), an unspecific glutamine-competitive irreversible KGA inhibitor, which is the most commonly used (30). Other molecules such as 968, BPTES or THDP17 have also been reported to inhibit glutaminase via different mechanisms with in vitro efficacy. However, despite all efforts, its high in vivo toxicity means it cannot be used for treatment $(31,32)$. Nevertheless, these studies suggest the possibility of many other scaffolds that inhibit glutaminase enzyme activity, enabling further investigations in the field.

Recently, it has become clear that overexpression of MYC causes glutamine addiction via a coordinated transcriptional program by the stimulation of glutamine uptake and metabolism, both directly and indirectly. MYC directly binds to the promoters and stimulates the expression of genes involved in glutaminolysis, such as the transporter ASCT2 and several enzymes utilizing glutamine (8). MYC also influences post-transcriptional regulation, as its overexpression correlates with a significant upregulation of glutaminase protein levels. This occurs indirectly by repression of the expression of miR-23a/b, which target GLS in the $3^{\prime}$ untranslated region (UTR) (33).
Here, we confirmed that glucose deprivation induces an overexpression of SLC1A5 leading to increased glutamine uptake, in order to sustain ATP generation through the TCA cycle. In fact, glutamine could sustain the oxidative TCA cycle in MYC-driven cells, even in a glucose deprivation environment, and cells would undergo apoptosis in the absence of this amino acid (34).

A further role for glutamine in cell protein translation stems from observations that a master regulator of protein translation, the mammalian target of rapamycin complex 1 (mTORC1), is responsive to glutamine levels (35). MYC and mTOR are involved in a positive feedback loop. mTORC1/ S6K1 controls MYC expression by modulating mRNA translation initiation efficiency via phosphorylation of the initiation factor elF4B. On the other hand, MYC promotes mTORC1 activity by facilitating leucine uptake (36). The study of Fuchs et al. in 2007 showed that silencing ASCT2 in hepatoma cells caused a reduction of mTOR activity leading to apoptosis. Glutamine taken up by ASCT2 stimulates leucine uptake by a parallel leucine/glutamine antiport catalyzed by the large neutral amino acid transporter 1 (LAT1), this promotes mTORC1 assembly and lysosomal localization (37,38). Furthermore, rapamycin decreases ASCT2 expression, thus indicating a reciprocal effect between this transporter and mTOR activity (37).

Our results show a feedback between MYC and mTOR under glucose withdrawal and ratify its role in the regulation of glutamine metabolism via ASCT2 and KGA. Metformin treatment caused a downregulation of both MYC and mTOR, as previously demonstrated $(39,40)$. In addition, a study by Akinyeke et al. in 2013 showed that the drug stimulates cell cycle arrest and apoptosis with a reduction of MYC protein levels by at least $50 \%$ in vitro and in vivo (41). They addressed the effects on the AMP-activated kinase (AMPK) pathway. However, a recent report suggested that MYC deregulation was a direct consequence of metformin-mediated upregulation of $\mathrm{miR}-33 \mathrm{a} / \mathrm{b}$, an intronic miRNA located within the sterol regulatory binding protein (SREBPs) genes (42).

Along these lines, we suggest that an increased use of glutamine as a carbon source for the cells, the greater the impact that metformin would have on them. Increased glutaminolysis was reported to be induced by a high $\alpha$-ketoglutarate/citrate ratio. Stress and hyperammonemia have been described to inhibit $\alpha$-ketoglutarate dehydrogenase, which catalyzes decarboxylation of $\alpha$-ketoglutarate in the TCA cycle. This increases the ratio and triggers enhanced glutaminolysis (43). The MYC oncogene controls the glutaminolytic pathway and induces glutamine addiction. Metformin use would reduce MYC levels in these cells and therefore, ASCT2 and KGA. This would result in a reduction in the production of metabolites and energy through this pathway and as an indirect consequence, a decrease in ammonia production that could be related to a decreased risk of HE development.

In conclusion, our findings lead us to hypothesize that the reduction of hyperammonemia in PCS rats caused by metformin treatment could be explained by a slight modulation of glutaminase activity. Besides, in vitro glucose withdrawal enhances the expression of genes involved in glutamine metabolism, which confers sensitivity to metformin by 
decreasing both absorption and degradation of this amino acid in the enterocyte. This could explain, at least in part, the lower prevalence of HE in patients taking metformin.

\section{ACKNOWLEDGEMENTS}

This research was supported by the Consejería de Innovación, Ciencia y Empresa of Junta de Andalucía (Spain): PIE-CTS-7991. Funders of the project had no role in study design, data collection and analysis, decision to publish, or preparation of the manuscript.

\section{REFERENCES}

1. Patel D, McPhail MJW, Cobbold JFL, et al. Hepatic encephalopathy. $\mathrm{Br} \mathrm{J}$ Hosp Med (Lond) 2012;73:79-85. DOI: 10.12968/hmed.2012.73.2.79

2. Ferenci P, Lockwood A, Mullen K, et al. Hepatic encephalopathy - Definition, nomenclature, diagnosis, and quantification: final report of the working party at the 11th World Congresses of Gastroenterology, Vienna, 1998. Hepatology 2002;35:716-21. DOI: 10.1053/jhep.2002.31250

3. Olde Damink SWM, Deutz NEP, Dejong CHC, et al. Interorgan ammonia metabolism in liver failure. Neurochem Int 2002;41:177-88. DOI: 10.1016/ S0197-0186(02)00040-2

4. Jover-Cobos $\mathrm{M}$, Davies $\mathrm{N}$, Jalan $\mathrm{R}$, et al. The rise of glutaminase in end-stage liver diseases, liver transplantation - Basic Issues. Prof. Hesham Abdeldayem (ed.), InTech; 2012. Available from: https://www.intechopen. $\mathrm{com} /$ books/liver-transplantation-basic-issues/the-rise-of-glutaminase-in-end-stage-liver-diseases DOI: 10.5772/29210

5. Romero-Gómez M, Jover M, Galán JJ, et al. Gut ammonia production and its modulation. Metab Brain Dis 2009:24:147-57. D0I: 10.1007/s11011008-9124-3

6. Romero-Gómez M, Ramos-Guerrero R, Grande L, et al. Intestinal glutaminase activity is increased in liver cirrhosis and correlates with minimal hepatic encephalopathy. J Hepatol 2004;41:49-54. DOI: 10.1016/j. jhep.2004.03.021

7. Scalise M, Pochini L, Panni S, et al. Transport mechanism and regulatory properties of the human amino acid transporter ASCT2 (SLC1A5). Amino Acids 2014:46:2463-75. DOl: 10.1007/s00726-014-1808-x

8. Wise DR, DeBerardinis RJ, Mancuso A, et al. Myc regulates a transcriptional program that stimulates mitochondrial glutaminolysis and leads to glutamine addiction. Proc Natl Acad Sci USA 2008:105:18782-7. DOI: 10.1073/pnas.0810199105

9. Rajendram R, Preedy VR, Patel VB. Glutamine in clinical nutrition. Glutamine Clin Nutr 2015:1-551. DOI: 10.1007/978-1-4939-1932-1

10. Levine AJ, Puzio-Kuter AM. The control of the metabolic switch in cancers by oncogenes and tumor suppressor genes. Science 2010;330:1340-4. DOl: 10.1126/science.1193494

11. Fendt S-M, Bell EL, Keibler MA, et al. Reductive glutamine metabolism is a function of the $\alpha$-ketoglutarate to citrate ratio in cells. Nat Commun 2013:4:2236. DOI: 10.1038/ncomms3236

12. García-Compeán D, Jaquez-Quintana J0, González-González JA, et al. Liver cirrhosis and diabetes: risk factors, pathophysiology, clinical implications and management. World J Gastroenterol 2009;15:280-8. DOI: 10.3748/wjg.15.280

13. Ampuero J, Ranchal I, Díaz-Herrero MM, et al. Role of diabetes mellitus on hepatic encephalopathy. Metab Brain Dis 2013:28:277-9. D0I: 10.1007/ s11011-012-9354-2

14. Butt Z, Jadoon NA, Salaria ON, et al. Diabetes mellitus and decompensated cirrhosis: risk of hepatic encephalopathy in different age groups. J Diabetes 2013;5:449-55. DOI: 10.1111/1753-0407.12067
15. Sigal SH, Stanca CM, Kontorinis N, et al. Diabetes mellitus is associated with hepatic encephalopathy in patients with HCV cirrhosis. Am J Gastroenterol 2006;101:1490-6. DOl: 10.1111/j.1572-0241.2006.00649.x

16. Odeh M, Sabo E, Srugo I, et al. Serum levels of tumor necrosis factor-alpha correlate with severity of hepatic encephalopathy due to chronic liver failure. Liver Int 2004;24:110-6. D0I: 10.1111/j.1478-3231.2004.0894.x

17. Goral V, Atayan Y, Kaplan A. The relation between pathogenesis of liver cirrhosis, hepatic encephalopathy and serum cytokine levels: what is the role of tumor necrosis factor alpha? Hepatogastroenterology 2011;58: 943-8.

18. Madiraju AK, Erion DM, Rahimi Y, et al. Metformin suppresses gluconeogenesis by inhibiting mitochondrial glycerophosphate dehydrogenase. Nature 2014;510:542-6. DOI: 10.1038/nature13270

19. Ampuero J, Ranchal I, Núñez D, et al. Metformin inhibits glutaminase activity and protects against hepatic encephalopathy. PLoS One 2012;7:e49279. DOI: 10.1371/journal.pone.0049279

20. Numata M. A modified technique to make a portacaval shunt in rats. Microsurgery 1983;4:243-4. DOI: 10.1002/micr.1920040409

21. Javeshghani S, Zakikhani M, Austin S, et al. Carbon source and Myc expression influence the antiproliferative actions of metformin. Cancer Res 2012:72:6257-67. DOI: 10.1158/0008-5472.CAN-12-2907

22. Chomzynski P, Sacchi N. Single-step method of RNA isolation by acid guanidinium thiocyanate-phenol-chloroform extraction. Anal Biochem 1987;162:156-9. DOI: 10.1006/abio.1987.9999

23. Bradford MM. A rapid and sensitive method for the quantitation of microgram quantities of protein utilizing the principle of protein-dye binding Anal Biochem 1976;72:248-54. DOl: 10.1016/0003-2697(76)90527-3

24. Heini HG, Gebhardt R, Brecht A, et al. Purification and characterization of rat liver glutaminase. Eur J Biochem 1987;162:541-6. DOI: 10.1111/j.14321033.1987.tb10673.x

25. Butterworth RF, Norenberg MD, Felipo V, et al. Experimental models of hepatic encephalopathy: ISHEN guidelines. Liver Int 2009;29:783-8. DOI: 10.1111/j.1478-3231.2009.02034.x

26. James LA, Lunn PG, Middleton S, et al. Glutamine oxidation and utilization by rat and human oesophagus and duodenum. Br J Nutr 1999;81:323-9. DOI: $10.1017 /$ S0007114599000574

27. McCreight LJ, Bailey CJ, Pearson ER. Metformin and the gastrointestinal tract. Diabetologia 2016;59:426-35. DOI: 10.1007/s00125-015-3844-9

28. Curthoys NP, Watford M. Regulation of glutaminase activity and glutamine metabolism. Annu Rev Nutr 1995;15:133-59. DOI: 10.1146/annurev. пu.15.070195.001025

29. Jover-Cobos $M$, Noiret $L$, Lee $K$, et al. Ornithine phenylacetate targets alterations in the expression and activity of glutamine synthase and glutaminase to reduce ammonia levels in bile duct ligated rats. J Hepato 2014;60:545-53. DOI: 10.1016/j.jhep.2013.10.012

30. Pinkus LM. Glutamine binding sites. Methods Enzymol 1977:46:414-27. DOI: 10.1016/S0076-6879(77)46049-X

31. Katt WP, Cerione RA. Glutaminase regulation in cancer cells: a druggable chain of events. Drug Discov Today 2014;19:450-7. DOI: 10.1016/j.drudis.2013.10.008

32. Díaz-Herrero MM, Del Campo JA, Carbonero-Aguilar P, et al. THDP17 decreases ammonia production through glutaminase inhibition. A new drug for hepatic encephalopathy therapy. PLoS One 2014:9:e109787. DOI: 10.1371/journal.pone.0109787

33. Gao P, Tchernyshyov I, Chang T-C, et al. c-Myc suppression of miR-23a/b enhances mitochondrial glutaminase expression and glutamine metabolism. Nature 2009;458:762-5. DOI: 10.1038/nature07823

34. Daye D, Wellen KE. Metabolic reprogramming in cancer: unraveling the role of glutamine in tumorigenesis. Semin Cell Dev Biol 2012;23:362-9. DOl: 10.1016/j.semcdb.2012.02.002 
35. Zhao Y, Liu H, Riker Al, et al. Emerging metabolic targets in cancer therapy. Front Biosci 2011;16:1844-60. DOI: 10.2741/3826. DOI: 10.2741/3826

36. Csibi A, Lee G, Yoon S-0, et al. The mTORC1/S6K1 pathway regulates glutamine metabolism through the elF4B-dependent control of c-Myc translation. Curr Biol 2014;24:2274-80. DOI: 10.1016/j.cub.2014.08.007

37. Fuchs $\mathrm{BC}$, Finger $\mathrm{RE}$, Onan $\mathrm{MC}$, et al. ASCT2 silencing regulates mammalian target-of-rapamycin growth and survival signaling in human hepatoma cells. Am J Physiol Cell Physiol 2007;293:C55-63. D0l: 10.1152/ ajpcell.00330.2006

38. Nicklin P, Bergman P, Zhang B, et al. Bidirectional transport of amino acids regulates mTOR and autophagy. Cell 2009;136:521-34. DOI: 10.1016/j. cell.2008.11.044

39. Wang SS, Hsiao R, Limpar MM, et al. Destabilization of MYC/MYCN by the mitochondrial inhibitors, metaiodobenzylguanidine, metfor- min and phenformin. Int J Mol Med 2014;33:35-42. DOl: 10.3892/ ijmm.2013.1545

40. Bolster DR, Crozier SJ, Kimball SR, et al. AMP-activated protein kinase suppresses protein synthesis in rat skeletal muscle through down-regulated mammalian target of rapamycin (mTOR) signaling. J Biol Chem 2002;277:23977-80. DOI: 10.1074/jbc.C200171200

41. Akinyeke T, Matsumura $S$, Wang $X$, et al. Metformin targets c-MYC oncogene to prevent prostate cancer. Carcinogenesis 2013;34:2823-32. DOI: 10.1093/carcin/bgt307

42. Pulito C, Donzelli S, Muti P, et al. microRNAs and cancer metabolism reprogramming: the paradigm of metformin. Ann Transl Med 2014;2:58. DOI: 10.3978/j.issn.2305-5839.2014.06.03

43. Ott $\mathrm{P}$, Vilstrup $\mathrm{H}$. Cerebral effects of ammonia in liver disease: current hypotheses. Metab Brain Dis 2014;29:901-11. D0I: 10.1007/s11011-0149494-7 